\title{
Regional differences in hospital admissions for ST-elevation and non-ST-elevation myocardial infarctions during the Coronavirus disease-19 (COVID-19) pandemic in Austria
}

\author{
Daniel Kiblboeck · Joerg Kellermair · Peter Siostrzonek · Clemens Steinwender
}

Received: 30 April 2020 / Accepted: 21 May 2020 / Published online: 12 June 2020

(C) Springer-Verlag GmbH Austria, part of Springer Nature 2020

To the editor

The first patients with Coronavirus disease-19 (COVID-

19) were reported in Wuhan, China at the end of 2019

[1]. In February 2020, Lombardy and Veneto in northern Italy reported a dramatic increase of COVID19 cases and became epicenters of the severe acute respiratory syndrome coronavirus 2 (SARS-CoV-2) outbreak in Europe [2]. On 25 February the first two cases of COVID-19 in Austria were confirmed in the neighboring region of Tyrol. In March, SARS-CoV-2 infections spread over Austria with the highest incidences in West Austria (Tyrol, Vorarlberg, Salzburg) (Fig. 1a). The Austrian government declared an emergency lockdown with a stay at home order on 16 March. The whole state of Tyrol and some regions of Salzburg were quarantined.

This survey was initiated by the Austrian Society of Cardiology to assess the incidence of acute coronary syndromes (ACS $=$ ST-elevation and non-ST-elevation myocardial infarction, STEMI and NSTEMI) in Austria at the beginning of the COVID-19 pandemic. A total of 19 cardiac catheterization centers reported the numbers of patients with STEMI and NSTEMI admitted per week over a period of 4 weeks from 2-29 March 2020 (calendar weeks 10-13).

In these 4 weeks, 777 patients with ACS (372 with STEMI and 405 with NSTEMI) were admitted to hospital. The incidence of STEMI and NSTEMI before

D. Kiblboeck $(\bowtie) \cdot$ J. Kellermair $\cdot$ C. Steinwender

Department of Cardiology and Medical Intensive Care,

Kepler University Hospital, Medical Faculty, Johannes Kepler

University, Linz, Austria

daniel.kiblboeck@kepleruniklinikum.at

P. Siostrzonek

Department of Cardiology, Ordensklinikum Linz

Barmherzige Schwestern, Linz, Austria the lockdown (weeks 10 and 11) compared to after the lockdown (weeks 12 and 13) decreased by $21 \%$ (STEMI: weeks $10+11: n=208$, weeks $12+13: n=164$, $\Delta=-44$ ) and by $44 \%$ (NSTEMI: weeks $10+11: n=259$, weeks $12+13: n=146, \Delta=-113)$, respectively. The number of STEMI and NSTEMI hospital admissions per week showed a strong negative correlation with the total number of confirmed COVID-19 infections (Spearman $\mathrm{r}=-1.0, p=0.08$ ). A strong decrease of ACS (STEMI and NSTEMI) was observed in all Austrian states (Fig. 1b). Remarkably, a stronger decrease was observed in West Austria with higher COVID-19 incidences (Tyrol, Vorarlberg, Salzburg) compared to East Austria with lower COVID-19 incidences (Upper Austria, Lower Austria, Styria, Vienna, Burgenland and Carinthia). The incidence of STEMI decreased by $29 \%$ in West Austria (weeks $10+11: n=51$, weeks 12+13: $n=36, \Delta=-15)$ and by $19 \%$ in East Austria (weeks 10+11: $n=157$, weeks 12+13: $n=128, \Delta=-29$ ), NSTEMI decreased by $65 \%$ in West Austria (weeks 10+11: $n=49$, weeks 12+13: $n=17, \Delta=-32$ ) and by $39 \%$ in East Austria (weeks 10+11: $n=210$, weeks 12+13: $n=129, \Delta=-81$ ) (Fig. 1c).

Cardiac catheterization centers around the world have reported dramatic declines in patients admitted to hospital for STEMI and NSTEMI during the COVID19 pandemic $[3,4]$.

Two different reasons may have contributed to this observation. First, governmental regulations (stay at home order, social distancing, quarantine) might have led to an actual decrease of STEMI and NSTEMI by less physical activity, less emotional stress in home office, less fine dust exposure and less non-SARS-CoV-2 viral infections, all potentially triggering ACS. Second, patient and health care-related factors (e.g. fear of infections, difficult access to health care specialists) have led to an unintended underdiagnosis of ischemic events. In any case, the observed decline of STEMI 
Fig. 1 a COVID-19 incidence per 100,000 inhabitants in different states of Austria [6]. b Decrease of ACS (STEMI and NSTEMI) during COVID-19 pandemic in different states of Austria (calendar week 10 to 13). c Decrease of STEMI and NSTEMI in West (Tyrol, Vorarlberg, Salzburg) vs. East Austria (Upper Austria, Lower Austria, Styria, Vienna, Burgenland, Carinthia) in calendar weeks 10 and 11 before vs. weeks 12 and 13 after the lockdown. ACS acute coronary syndrome, COVID-19 Coronavirus disease-19, STEMI ST-elevation myocardial infarction, NSTEMI non-ST-elevation myocardial infarction

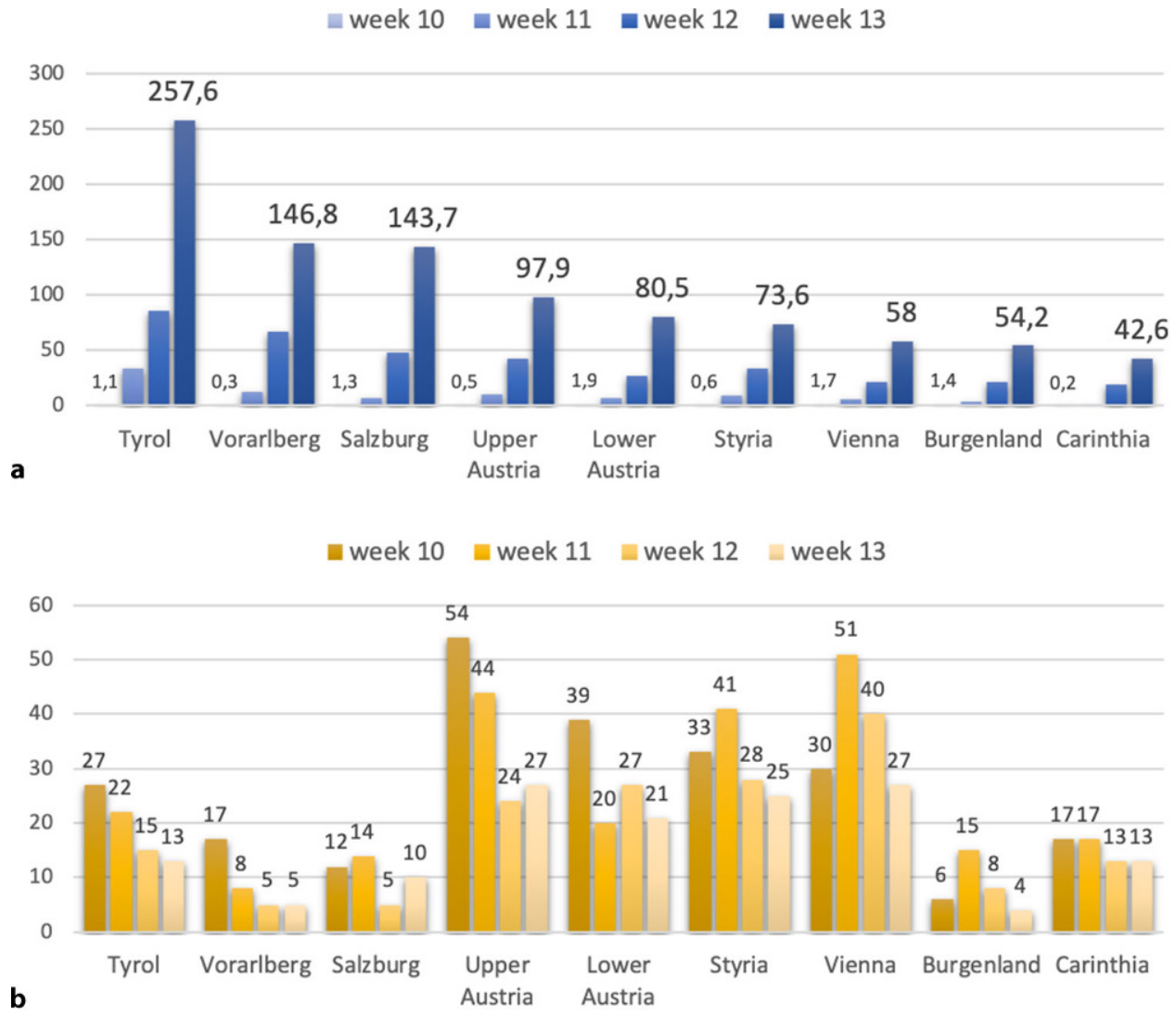

week $10+11$ week $12+13$

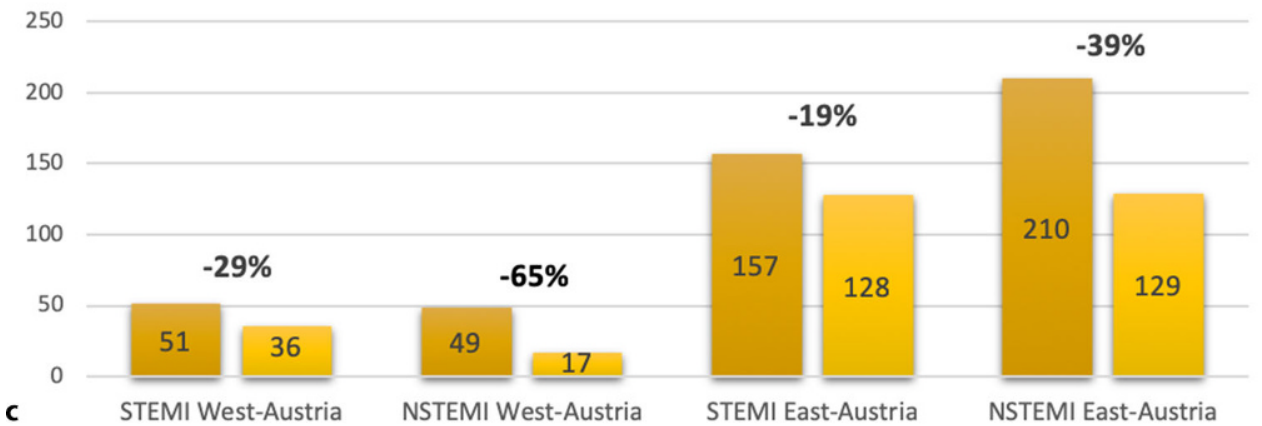

and NSTEMI hospital admissions is a cause for concern, as a higher than usual proportion of untreated patients with ACS may result in an increased mortality due to arrhythmias and heart failure [5].

In conclusion, our survey demonstrates that the COVID-19 pandemic in Austria led to fewer hospital admissions for STEMI and NSTEMI with an even higher decrease in West Austria with higher COVID19 incidences.

Acknowledgements The authors would like to thank the participating cardiac catheterization centers for supporting this survey of the Austrian Society of Cardiology. Affiliation of the participating cardiac catheterization centers (in alphabetical order): Bruck an der Mur: Landeskrankenhaus Hochsteiermark, Innere Medizin, Prim. Univ. Prof. Dr. Gerald Zenker; Eisenstadt: Krankenhaus der Barmherzigen
Brüder, Innere Medizin 1 - Kardiologie, Prim. Univ.-Prof. Dr. Rudolf Berger; Feldkirch: Landeskrankenhaus Feldkirch, Innere Medizin 1 - Kardiologie, Prim. Priv.-Doz. Dr. Matthias Frick, OA Dr. Walter Marlon; Graz: Medizinische Universität Graz, Kardiologie, Univ.-Prof. Dr. Andreas Zirlik; Graz: Landeskrankenhaus Graz-West, Department für Kardiologie, DeptL Dr. Wolfgang Weihs, Priv.-Doz. Dr. Herwig Schuchlenz; Innsbruck: Medizinische Universität Innsbruck, Innere Medizin 3 - Kardiologie, Prim. Univ.-Prof. Dr. Axel Bauer, Univ.Prof. Dr. Bernhard Metzler; Klagenfurt: Klinikum Klagenfurt, Innere Medizin und Kardiologie, Prim. Priv.-Doz. Dr. Hannes Alber; Linz: Kepleruniversitätsklinkum Linz, Innere Medzin I - Kardiologie, Prim. Priv.-Doz. Dr. Clemens Steinwender, OA Dr. Michael Grund; Linz: Ordensklinikum Linz Elisabethinen, Interne 2 - Kardiologie, Prim. Mag. Dr. Josef Aichinger; Salzburg: Universitätsklinikum Salzburg, Innere Medizin 2 - Kardiologie, Prim. Univ.-Prof. Dr. Uta Hoppe; St. Pölten: Universitätsklinikum St. Pölten, Innere Medizin 3, Prim. As- 
soc.-Prof. Dr. Harald Mayr, OA Dr. Paul Vock, OÄ Dr. Gudrun Lamm; Wels: Klinikum Wels-Grieskrichen, Innere Medizin 2 Kardiologie, Prim. Priv.-Doz. Dr. Ronald Binder; Wien: Medizinische Universität Wien, Innere Medizin 2 - Kardiologie, Univ.-Prof. Dr. Christian Hengstenberg, Univ.-Prof. Dr. Irene Lang; Wien: Krankenhaus Nord, Abteilung für Kardiologie, Prim. Priv.-Doz. Dr. Georg Delle Karth; Wien: Wilhelminenspital, Innere Medizin und Kardiologie, Prim. Univ.-Prof. Dr. Kurt Huber, OA Univ.-Doz. Dr. Alexander Geppert; Wien: Sozialmedizinisches Zentrum Süd - Kaiser-Franz-Josef-Spital, 5. Med. Abteilung, Prim. Univ.-Prof. Dr. Andrea PodczeckSchweighofer, Univ-Prof. Dr. Günter Christ; Wien: HanuschKrankenhaus, 2. Medizinische Abteilung - Kardiologie, Prim. Dr. Johann Sipötz, OA Dr. Michael Winkler; Wien: Krankenhaus Rudolfstiftung, 2. Abteilung mit Kardiologie, Univ.Prof. Dr. Franz Weidinger; Wiener Neustadt: Landesklinikum Wiener Neustadt, Innere Medizin - Kardiologie, Prim. Univ.Doz. Dr. Franz Xaver Roithinger

Conflict of interest D. Kiblboeck, J. Kellermair, P. Siostrzonek and C. Steinwender declare that they have no competing interests.

\section{References}

1. MunsterVJ,Koopmans M,DoremalenN, van RielD, deWitE. A novel coronavirus emerging in China-key questions for impact assessment. NEngl J Med. 2020;382(8):692-4.
2. Rosenbaum L. Facing Covid-19 in Italy-ethics, logistics, and therapeutics on the epidemic's front line. N Engl J Med. 2020; https://doi.org/10.1056/NEJMp2005492.

3. Garcia S, Albaghadadi MS, Merai PM, etal. Reduction in STsegment elevation cardiac catheterization laboratory activations in the United States during COVID-19 pandemic. J Am Coll Cardiol. 2020; https://doi.org/10.1016/j.jacc. 2020.04.011.

4. Rodriguez-Leor O, Cid-Alvarez B, Ojeda S, et al. Impact of the COVID-19 pandemic on interventional cardiology activity in Spain. Rec Interv Cardiol. 2020; https://doi.org/ 10.24875/RECIC.M20000120.

5. Metzler B, SiostrzonekP, Binder RK, Bauer A, Reinstadler SJ. Decline of acute coronary syndrome admissions in Austria since the outbreak of COVID-19: the pandemic response causes cardiac collateral damage. Eur Heart J. 2020; https:// doi.org/10.1093/eurheartj/ehaa314.

6. Official COVID19 dashboard public information. Federal Ministry Republic of Austria Social Affairs, Health, Care and ConsumerProtection. https://info.gesundheitsministerium. at/ ?l=en

Publisher's Note Springer Nature remains neutral with regard to jurisdictional claims in published maps and institutional affiliations. 